\title{
"The cripple walked! The cripple talked!": Contextualising Sign Language and Audism in Memoirs of Deafness
}

\author{
Bonjyotshna Saikia \\ Research Scholar, Department of English, Tezpur University, Assam, India. \\ ORCID id: 0000-0001-6253-9333. Email:bonjyotshnasaikia263@gmail.com
}

\begin{abstract}
The hegemony of speech has created notions of superiority among the hearing community propagating an audist attitude, which Tom Humphries defines as a form of discrimination towards the deaf in a hearingdominant society. Deafness as a social phenomenon necessitates a reconsideration of the status of speech and sound. The huge chasm between the hearing and the deaf can be resolved only through the normalisation of every mode of communication. In a close reading of two memoirs of deafness: Henry Kisor's What's That Pig Outdoors? (1990) and Madan Vashishta's Deaf in Delhi (2006), this article examines the similar experiences of the deaf from different linguistic, national and cultural backgrounds. Drawing theoretical insights from Leonard Davis, Neil Stephen Glickman, and Dirksen Bauman, among others, the article argues that these memoirs enable a non-essentialised perception of deafness and question the preconceived stance in relation to language. In so doing, the article also addresses the status of Sign Language as a means of communication in contemporary times.
\end{abstract}

Keywords: Audism, Deaf memoirs, Derrida, Deaf Identity, Sign Language, Phonocentrism

\section{Introduction}

Deafness as a social phenomenon necessitates a reconsideration of the status of speech and sound. Rather than conceiving exclusively in medical terms, the underpinnings of being deaf in a hearing world requires careful consideration through an interdisciplinary approach including the fields of linguistics, humanities, philosophy, psychology, and sociology. The 1970s saw a remarkable leap in the recognition of the deaf identity in academia. Instead of viewing deafness as a disability, they called for a unique identity of their culture and the sign languages. Dirksen Bauman explores the philosophy apropos language and human identity within the context of audism. Tom Humphries (1975), credited with coining the term, defines audism as "the notion that one is superior based on one's ability to hear or behave in the manner of one who hears"(as cited in Bauman, 2004, p. 240). In a comprehensive study on the subjugation of the deaf, Harlan L. Lane in his Mask of Benevolence (1992) examines the role of the "dominating, restructuring, and exercising authority over the deaf community" in sustaining the institution of oppression and discrimination (p. 43). Similarly, Lennard Davis observes how the identity of deaf people seems to

This Open Access article is published under a Creative Commons Attribution Non-Commercial 4.0 International License (http://creativecommons.org/licenses/by-nc/4.0/), which permits non-commercial re-use, distribution, and reproduction in any medium, provided the original work is properly cited. For citation use the DOI. For commercial re-use, please contact editor@rupkatha.com. 
be circumscribed around the "disability-difference binary" which threatens to denigrate them to the margins (Davis, 2002, p.9). The sign/speech or deaf/hearing dichotomy entraps the deaf person in the rhetoric of exclusion as it burgeons on oppositions.

This paper aims to reconnoitre the work of two Deaf writers --one American and one Indian-- to demonstrate how despite the cultural and linguistic differences, they share a common Deaf identity. Henry Kisor's memoir What's That Pig Outdoors? (1990) describes the experiences of a deaf individual in a culturally hearing world. His ability is not afflicted by his inability to hear. The success of Kisor as the book review editor at the Chicago Daily News and the Chicago SunTimes is a telling reminder of his accomplishments. Apart from editorship, he has penned mystery novels, and many non-fiction works. A licensed pilot, Kisor has narrated his experience in Flight of the Gin Fizz: Midlife at 4500 Feet (1997), which is indeed a reenactment of a flight by Cal Rodgers's in 1911. Kisor's memoir of deafness further describes the history of the sign versus oral controversy, and the various technological innovations during the late twentieth century introduced to assist people with hearing loss, tinged with his personal experiences. The title of the book is based on 'an episode of acoustic flatulence' as Howard R. Busby calls it, reflecting the quirks of lip-reading (1991, p. 311). Henry Kisor has adopted speech reading instead of Sign language as his means of communication; when the five-year-old son inquired about the grumblings of his father's stomach as "What's that big loud noise?" Kisor lip-reads the question as "What's that pig outdoors?", illustrating one of the many vagaries of the method. Similarly, Madan Vasishta's Deaf in Delhi (2006) recounts his life as a deaf person in Indian society. As a child, he was suddenly thrown into the world of silence when he lost his hearing ability. The extraordinary experience of growing up deaf in India started in 1952 when Vasishta was eleven years old. The memoir depicts his illustrious life from herding cattle to becoming a government photographer in Delhi. The narrative ends with his arrival at the Gallaudet University in America. Deaf in Delhi reveals the marginal condition of Deaf community in India, whereas his American experiences find place in his next memoir Deaf in DC (2010). The memoirs encapsulate the precarious nature of the spoken world.

\section{D/deaf identity}

The nexus of identity and culture among the deaf people can be discerned through their bilingual and bicultural lives. To broaden the spectrum of analysis of deaf identity, there is a divide between Deaf with the uppercase $D$ and deaf with the lowercase $d$. The former refers to the community of deaf with a distinct culture of their own whose first language is a signed language; the latter, however, alludes to the audiological implication of hearing loss and applicable to a diverse group who are mainly part of the hearing culture (Myers \& Fernandes, 2010). However, this categorisation is disputed by scholars who consider that such a taxonomy would eventually exclude those who do not identify with the community at large. For instance, Monaghan and Schmaling observe that not all deaf children grew up in an exclusively deaf environment; some may never meet another deaf to communicate in sign languages (2003, p. ix-xii). The division of $D /$ deaf is more of an accommodation to diversity. Some 'deaf' with the small-d who have lost their hearing during their childhood or adulthood and yet choose to stay with spoken mode as the language of preference and remain members of the hearing culture. 
Henry Kisor and Madan Vasishta's narratives are replete with instances reflecting the inconsistency of the division. While Kisor relies on his lip-reading or 'speech-reading' skills, Vasishta uses the Indian Sign Language to communicate. They have lost their hearing during their childhood after acquiring the rudiments of speech, hence, they can be grouped under 'postlingual deaf'; however, Kisor lost it when he was still very young to remember whatever he had learnt. Having said that, Kisor could have easily opted for Sign language, yet he chose to interact with his speech. Vasishta, on the other hand, was fluent in his speech when he lost his hearing, nonetheless chose Sign language as his medium to feel more connected with the Deaf community, while also using speech to communicate with his family.

Vasishta's identity with both the hearing and Deaf cultures can be read as an example of bicultural identity, postulated by Neil Stephen Glickman (1993). In a similar development, Mcllroy (2010) terms the bicultural identity as "DeaF identity" which he considers as a space of transition between the hearing clique and the Deaf community. The uppercase $\mathrm{F}$ in 'DeaF' foregrounds the fluid identity of the deaf person (Mcllroy \& Storbeck, 2011). However, Kisor can be identified in terms of the culturally hearing as he perceives his deafness as disability:

"Hearing impaired seems to be the most accurate term for people like me. After all, my hearing was impaired all those decades ago ---impaired into nonexistence. This is why I still think of my deafness as a disability, not a culture" (Kisor, 1990/2010, epilogue)

Kisor can be conveniently grouped under Glickman's "culturally hearing" identity who perceive deafness as a disability. But a deeper probe would reveal otherwise. Just after stating about his deafness, he questions his assumptions, and contends that deafness is not a disability for those who "don't feel they suffer from not hearing" (Kisor, 1990/2010, epilogue). Instead he renounces the "obsolete and benighted views many ignorant hearing people have of the deaf" who ostensibly empathise with those who cannot hear (Kisor, 1990/2010, epilogue). Kisor criticises the use of umbrella terms to club every deaf individual together without taking into consideration their different experiences of deafness.

\section{Phonocentrism and Sign language}

Dirksen Bauman in his "Listening to Phonocentrism with Deaf Eyes: Derrida's Mute Philosophy of (Sign) Language" (2008) contends that Derrida's works foregrounded the importance of nonphonetic communications and an alternative language system. The power relations between hearing and deaf can be conquered through the repudiation of certain notions which define speech as the only 'truth'. Bauman reiterates the Derridian reading of language as an alternative means which abjures the privileging of speech and calls for a more flexible means of communication. The fact that voice and language is one of the many facets of communication which apparently have no "natural connection" is highlighted throughout the narratives (Bauman, 1977, p. 316). Kisor and Vasishta's narratives provide ample evidence of their success achieved with sheer determination and hard-work; their deafness rarely hindering the process.

In his critique of phonocentrism, Derrida calls attention to the superficiality of the grandeur assumption of speech over writing. Phonocentrism is a notion which assumes that "speech is the 
most fully human form of language" (Bauman, 2004, p. 243). In Of Grammatology (1974), Derrida states that "the system of 'hearing (understanding)-oneself-speak' through the phonic substance...has necessarily dominated the history of the world during an entire epoch, and has even produced the idea of the world, the idea of world-origin" (p. 8). The non-phonetic forms of communication are also crucial to understand language as a whole. The power of speech over other means of language or communication has shaped the orthodox belief systems of the superiority of hearing people. Sign as a non-phonetic communication is accorded the status of "other" in the language system. He indicates the redundancy of veneration for phonetic writing at the dismissal of other non-phonetic forms of writing which is evidently linked to what J. Nelson describes the phenomenology of language to identity formation, which takes into granted the ability to 'hear-oneself-speak' to be the fundamental basis of the philosophy of existence.

The ontological significance of speech in relation to language and identity is questioned by J. Nelson in her critical essay on the literature of American Sign Language (2006). Nelson delineates the presumptions based on which the voice is positioned in an authoritative stance, in the absence of which a deaf person is believed to be non-existent. Her experience as a deaf person bears testimony to this practice whereby as a child she had to undergo rigorous training to make her speech as "perfect" as a "hearing" person's (Nelson, 2006, p. 127). The endless time committed to that sort of articulatory education reiterates "the institutionalisation of our phonocentric and audist metaphysical orientation" (Bauman, 2004, p. 245). This itemisation of speech therapy in deaf education can be read as the manifestation of an audist approach discreetly rendering itself through the quotidian act of regulating a deaf person. The process entails a series of rituals that validates hearing bodies vis-a-vis the deaf.

Bauman's application of phonocentrism to the deaf experience is contested by Myers and Fernandes. They argue that Derrida's study of the western assumption of speech over writing is based on the four archetypal western philosophers, hence, it cannot be generalised to include the experiences of all deaf individuals. They view Derrida's philosophy as biased on account of his representation of the entire western metaphysics through the four philosophers. It is important to note that Myers and Fernandes reminds that other linguists and theorists have exposlutated this theory and argues that western culture venerated writing above speech. Their critique is important as it calls for a broadening of the scope of what constitutes language and emphasising the need to move beyond the restricted area of the western metaphysics. However, Bauman's exploration of the Derridian theory to the experience of deafness cannot be ignored.

The critique of phonocentrism is universal as it points to the fact that Sign languages are still looked down upon in the hearing culture. It is only during the mid-twentieth century that Sign has been recognised as one of the many modes of communication along with oral language (Ruben, 2005). Otherwise throughout history, linguistic communication and education of the deaf (if any) has been characterised by acrimony as they viewed the "incontestable superiority of speech over signs in restoring the deaf-mute to society" (International Congress of Teachers of the Deaf, Milan, 1880, as cited in Ruben, 2005, p. 467). The notion to 'restore the deaf-mute' only through speech marginalised Sign languages and attributed the status of alien, or exotic. For instance, when Vasishta and his friends sign in public spaces, they are stared upon by the people; some people even mock them. Derrida claims that "the nonphonetic moment menaces the history and the life of the spirit as self-presence in the breath, it is because it menaces 
5 "The cripple walked! The cripple talked!": Contextualising Sign Language and Audism in Memoirs of Deafness

substantially...Nonphonetic writing breaks the noun apart" and hence disrupt the traditional grammatical system (1997, p. 26). Sign language is a "spatial language" which is made by "using location of signs in space to express relationships among signs" (Brennan, 2002, p. 185). The "visual-kinetic-spatial" nature of the Sign language questions the basic linear nature of speech (Bauman, 2004, p. 244).

Vasishta was introduced to Sign language for the first time when he arrived in Delhi. The sight of the rhythmic movement of the hands and fingers opened a new world for him. He realised that the spoken word is not the only requirement to communicate, as "their expressive faces and mannerisms demonstrated that they were communicating with each other just like two hearing people would by speaking" (Vasishta, 2006, p. 98). He decided to learn this newly-found skill of Signing; however, he was disappointed when he approached a hearing clerk for help. The clerk questioned him regarding the necessity for Sign language, since he was fluent in his speech. Nevertheless, he gave Vasishta a handbook to learn Signs. The perception of Sign language as inferior is evident in the brief encounter between a deaf and a hearing person. He did not take heed of the hearing person's advice and "fell in love with sign language" as it enabled his entry in the Deaf community (Vasishta, 1991, p. 101).

It is noteworthy to mention that Vasishta's initial approach towards his deafness was not in a positive light. He was aware of the inferior position that deaf people occupy in society. His initial response to his deafness can be read in the light of Judith Butler's theory of 'linguistic vulnerability'. In her Excitable Speech (1990), Butler underlines the process of 'hate speech' and 'naming' in the formation of one's identity. The process of demeaning others through labelling them based on their physical attribute is derogatory and affects the individuals. Vasishta was "petrified" by the thought of the "extremely offensive and derogatory words" used to describe the deaf in his village (2006, p. 5). He "shuddered" at the thought of being called "mentally retarded", a term labelled to a deaf resident (p.5). His deafness affected his interaction with others. He felt neglected since people lost interest in communicating with him, as "hearing people do not make much effort to communicate with the deaf" (p. 67). However, this is in stark contrast to his life after his arrival in the city where he explored every avenues available for him, finally making his way to the Gallaudet University.

\section{Phonocentrism and Audism}

Dirksen Bauman defines audism in terms of David Wellman's definition of racism. He draws parallel between the two stating that audism is a "system of advantage based on hearing ability" (Bauman, 2004, p. 241). He traces the prerogatives of hearing people which are denied to the deaf. The institutions that are meant to serve the deaf population are also sites of audism which sometimes blur the lines between the deaf professors and hearing professors. Though accessible to both, Bauman provides insights from Gallaudet University itself where the gap in communication renders marginal status to the Deaf in terms of decision-making and information, in turn stripping them of having a major stake within the institution. Tom Humphries's definition of audism illustrates the familiar externalisation of the discriminition meted out to the deaf: 
"[Audism] appears in the form of people who continually judge deaf people's intelligence and success on the basis of their inability in the language of the hearing culture. It appears when the assumption is made that the deaf person's happiness depends on acquiring fluency in the language of the hearing culture. It appears when deaf people actively participate in the oppression of the other deaf people by demanding of them the same set of standards, behaviour, and values that they demand of hearing people" (as cited in Bauman, 2002, p. 240)

The definition offers various instances which exhibit audism. It points to the different notions and conducts that presupposes the primacy of hearing over deaf. These attitudes shape the lives of the deaf people who go through discrimination on a regular basis. Henry Kisor is often asked "Are you happy?", when he answers in the affirmative, they find it hard to believe (Kisor, 1990/2010, ch. 11). He is often confronted with suspicious looks as they assume that underneath the "happy" person there is a "forlorn and despondent" heart (Kisor, 1990/2010, ch. 11). Kisor further adds that most often than not, he faces discrimination from the Deaf community, as he claims himself to be an oralist.

The imposition of Sign language on deaf children also reflects the implicit audist attitudes within the Deaf community. Some make the child's early education their business by manipulating the parents into sending their deaf child to deaf schools only claiming that " $t]$ hey were the experts, not the parents, only they would make the decisions" (Kisor, 1990/2010, ch. 11). Similarly, Paddy Ladd describes the irony of these 'experts' as she was repeatedly reminded of her deafness and her inability to teach the deaf. As a child she was sidelined within the Deaf community for she had traces of hearing left, but she was denied access to a hearing school on grounds of her 'disability'. The constant anomaly between the deaf and hearing has been perpetuated by a section within the Deaf community, making them an "outcast from both" (Kisor, 1990/2010, ch.11).

Tom Humphries observes that audism "appears in the class structure of the deaf culture when those at the top are those whose language is that of the hearing or closest to it" (as cited in Bauman, 2004, p. 240). The intricacies of the systemic abuse of power is difficult to discern as it creates a facade of rationalisation. The narratives provide two contrasting accounts of Tom Humphries's observation. For instance, Henry Kisor experiences discrimination from the Deaf community as he is much inclined towards the hearing world. Kisor expresses his dislike for some of the educators of deaf and many deaf ideologies as they take his life to be an isolated lot. They assume that his reliance on speech and lipreading throws him into a dark world of loneliness in comparison to his peers who use Sign to communicate. He is declared as a "poor shadow of a hearing person, not a contented and fulfilled deaf person. I belong neither to the hearing world nor to the deaf community, they say; I am an outcast from both" (Kisor, 1991/2010, ch. 11). He faces discrimination in the hearing as well as the Deaf culture.

However, the audist attitude is more explicit in the hearing culture, where he has carved a space of his own. Studies have concluded that the deaf find themselves lost in a sound-dominant world affecting social and emotional learning (Moeller, 2007; Fellinger et al., 2009); others have evidently linked depressive symptoms and "adaptive emotion regulation" to the loss of hearing (Eldik, 2005; Kanuk, 2006; Ladoucer, 2005). Though published a decade before these studies were conducted, Kisor describes the insidiousness of "some experts on deafness" on categorising him 
7 "The cripple walked! The cripple talked!": Contextualising Sign Language and Audism in Memoirs of Deafness

into the subset of the "deaf personality" which includes immaturity, rigidity, egocentric, impulsiveness which according to the experts were the consequences of the lack of emotional development on the part of the deaf child (Kisor, 1990/2010, ch.11). He also describes his experiences with Miss Jones, the tester (assistant professor of audiology) of the Northwestern University whose condescending approach towards his deafness is reflected when she insists Henry Kisor to "accept [his] deafness" (Kisor, 1990/2010, ch.7).

Similarly, Vasishta's experiences with the All India Federation of the Deaf (AIFD) entails a series of encounters where the systemic oppression within the Deaf community is evident. B.G. Nigam, the general secretary of the AIFD, was the most powerful and successful deaf person in India. But he was despised by the other deaf people due to his corrupted nature. He was at the top of the well-defined class hierarchy within the Deaf community. Vasishta's visits to the Deaf clubs showcase the kind of distinct class structure within them. The Delhi Deaf Association, for instance, had contacts with some powerful politicians and enjoyed various incentives which were otherwise denied to other deaf people. However, an inner conflict within the group resulted in the creation of the AIFD by Mr. Nigam which hawked all the attention and soon the DDA was on the verge of collapse. The way Nigam plotted the fall of DDA by pinning the entire blame on Sharma is a telling sign of discrimination within the Deaf community. Vasishta claims that besides his old life which consists of communicating with his family who trace words on their palms for him to study, he led a completely different life in the Deaf community and the All India Photography Institute for the Deaf (PID).

The binary between human and non-human informs the distinction between hearing and deaf. The institutional audism is more pertinent in Darwin's Theory of Evolution which rendered a non-human status to deaf people (Baynton, 1996). For instance, Johann Conrad Amman writes about the Deaf as "little do they differ from animals", or Lewis Dudley, the American Oralist who conveys a similar judgment when he describes his deaf students as "human in shape, but only half-human in attributes" (cited in Bauman, 2004, p. 243). As Bauman explains, for many centuries the Deaf were seen as inhuman due to their lack of speech. Citing instances from the nineteenth and early twentieth centuries, Bauman reveals an uncanny sense of discrimination that lurked in the minds of the educators of the Deaf. He quotes Abbe Roch-Ambrose Ricard who referred to the uneducated deaf pupil as "perfect nonentity, a living automaton...The deaf person lacks even that unfailing instinct directing animals destined only to have that as their guide" (p. 243). Through the demarcation of the speaking/non-speaking being, the Deaf are imposed upon to adopt the stringent rules of the hearing world. But the developments in the ASL linguists and neurolinguistics assert that the definition of language has always been incomplete. The identity of humans based on their speaking capacity is a coloured concept which jeopardises the relationship between Deaf and hearing people. Speech is in fact just one of the many aspects of human language.

\section{Conclusion}

This article addressed the hegemony of the hearing world through the lens of two narratives of deafness. In order to understand the quotidian experience, we need to move beyond the medical definitions of deafness. The presumed ontological views on language and thought is directly 
linked to the idea of the self and identity. Deaf identity is not a fixed notion, rather it is a nexus of language, culture, and belongingness. Brenda Brueggemann in her Lend Me Your Ear(1999) talks about the interaction between apparently contradictory terms where an hyphenated identity can be helpful in subverting the binary oppositions resulting in a fluid and ingenious constructions of identity, mirroring the complex realities of deaf people today. In a pluralist society, Deaf culture is not an outcast group; they are members of a language-based culture with its own sets of common and established language. The interaction with a deaf person is, what David Wright (1972) calls, an 'excellent litmus test' of a hearing person's character. The huge chasm between the hearing and the deaf can be resolved only through the normalisation of every mode of communication, be it Sign or lip-reading. However, this article also endeavoured to question the homogenisation of deaf people. Every deaf person is not a member of the self-contained Deaf culture.

While addressing these differences, this article undertakes a careful examination of the experiences rendered through the memoirists. They have defied the audist attitudes and questioned the general assumptions towards their deafness. Studies have often claimed that one of the major obstacles in the formation of social relationships between children with hearing loss and their hearing peers is the spoken language. Speech intelligibility constitutes an important part in the spoken language. According to Eisenberg (2007), speech of the deaf children tends to have a monotonous tone, and inappropriate resonance, pitch, or intensity. The not-so-common speech acts as a barrier of communication among young children resulting in loneliness. The studies suggest that deafness influences the individual's social interaction thus affecting their mental and physical health (Kral \& O'donoghue, 2010). However, as far as the memoirs are concerned, these studies tend to generalise the experiences of a select group within the D/deaf community. Undeniably, the D/deaf have their own share of emotional turmoil, which is common even with their hearing peers, otherwise as Kisor says "[l]ife without hearing has been fine and fulfilling" (1991/2010, epilogue). Deaf people have a distinct social circle which refutes such claims as the exaggeration of hardships faced only due to their deafness.

\section{References}

Anglin-J, H. (2011). "Sign, Play and Disruption: Derridean Theory and Sign Language". Culture, Theory and Critique, 52(1), 29-44. DOI: 10.1080/14735784.2011.621665

Bauman, H-D. L. (1997). "Towards a Poetic of Vision, Space, and the Body". In Leonard J. Davis (ed.), The Disability Studies Reader. New York: Routledge, 315-31.

Bauman, H-D. L. (2004). "Audism: Understanding the Metaphysics of Oppression". Journal of Deaf Studies and Deaf Education, 9(2), 239-46.

Bauman, H-D. L. (2008). "Listening to Phonocentrism with Deaf Eyes: Derrida's Mute Philosophy of (Sign) Language". Essays in Philosophy: A Biannual Journal, 9(1).

Busby, H. R. (1991). "What's That Pig Outdoors? A Memoir of Deafness by Henry Kisor (review). America Annals of the Deaf, 136(4). DOI: 10.1353/aad.2012.0517

Butler, J. Excitable Speech. A Politics of the Performative. New York: Routledge.

Derrida, J. (2004). Of Grammatology ( G. C. Spivak, Trans.). Baltimore, MD: John Hopkins University Press.

Davis, L. (2002). Bending Over Backwards: Disability, Dismodernism and Other Difficult Positions. NY: New 
9 "The cripple walked! The cripple talked!": Contextualising Sign Language and Audism in Memoirs of Deafness

York University Press.

Eisenberg L. S. (2007). "Current State of Knowledge: Speech Recognition and Production with Hearing Impairment". Ear and Hearing, 28, 766-72. DOI: 10.1097/AUD.0b013e318157f01f

Eldik, T. V. (2005). "Mental Health Problems of Dutch Youth with Hearing Loss as Shown on the Youth Self Respect". American Annals of the Deaf, 150, 11-16. DOI: 10.1353/aad.2005.0024

Eldik, T. V., P. Treffers, J. Veerman, F. Verhulst. (2004) "Mental Health Problems of Deaf Dutch Children as Indicated by Parents' Responses to the Child Behaviour Checklist." American Annals of the Deaf, 148, 390-95. DOI: 10.3109/00048670903489866.

Fellinger, J., D. Holdinger, C. Beitel, M. Laucht, D. P. Goldberg. (2009). "The Impact of Language Skills on Mental Health in Teenagers with Hearing Impairments". Acta Psychiatrica Scandinavica, 120, 153-59. DOI: $10.1111 /$ j.1600-0447-2009.01350.x

Fernandes, J. \& S. Myers. (2010). "Inclusive Deaf Studies: Barriers and Pathways". Journal of Deaf Studies \& Deaf Education, 15(1), 3-16. DOI: 10.1093/deafed/enp018.

Glickman, N. S. (1993). "Deaf Identity Development: Construction and Validation of a Theoretical Model". Doctoral Dissertations Available from Proquest. AAI9329612. https://scholarworks.umass.edu/dissertations/AAI9329612.

Kral, A., \& G. M. O' donoghue. (2010). "Profound Deafness in Childhood." New England Journal of Medicine, 363(15), 1438-1450. DOI: 10.1056/NEJMra0911225.

Kisor, H. (2010). What's That Pig Outdoors?: A Memoir of Deafness (1990). Chicago: University of Illinois Press.

Lane, H. L. (1992). The Mask of Benevolence: Disabling the Deaf Community. New York: Alfred Knopf. Mcllroy, G. W. (2010). Discovering Deaf Identities: A Narrative Exploration of Educational Experiences of Deaf Identity. Saarbrucken, Germany: Lambert Academic Publishers.

Moeller, M. P. (2007). "Current State of Knowledge: Psychosocial Development in Children with Hearing Impairment". Ear and Hearing, 28, 729-739. DOI: 10/1097/AUD.0b013e318157f033.

Myers, S. S. \& J. K. Fernandes. (2010). "Deaf Studies: A Critique of the Predominant U.S. Theoretical Direction". Journal of Deaf Studies and Deaf Education, 15(1), 30-49. DOI: 10.1093/deafed/enp017.

Nelson, J. L. (2006). "Textual Bodies/Bodily Texts". In H-D. L. Bauman, J. L. Nelson, \& H. M. Rosé (eds.), Signing the Body Poetic: Essays in American Sign Language Literature. Berkeley, CA: University of California Press.

Ruben, R. J. (2005). "Sign Language: Its history and contribution to the understanding of the biological nature of language". Acta Oto-Laryngologica, 125(5), 464-7. DOI: 10.1080/00016480510026287.

Vasishta, M. (2006). Deaf in Delhi: A Memoir. Washington, D.C.: Gallaudet University Press.

Bonjyotshna Saikia is Ph.D. Research Scholar in the Department of English, Tezpur University, Assam, India. She is currently working on Domesticities of the Nineteenth and Twentieth Century. Her research interests include Health Humanities, and Gender Studies. 